\title{
Excelencia del servicio
}

La filosofía de la gerencia de servicio requiere que cada parte de la organización funcione en torno a las necesidades del cliente y sugiere, que todos tienen algo que aportar para lograr que el cliente quede satisfecho con el servicio. Toda persona de la organización que tenga contacto directo con el cliente es responsable de brindar la más clara información y hacer todo lo que esté a su alcance para garantizar respuestas precisas a los interrogantes que se manifiesten, además de alternativas de solución asertivas a las necesidades expresadas. El concepto de gerencia de servicio intenta desarrollar una cultura que convierta el hecho de brindar un excelente servicio al cliente en una misión reconocida por todos los miembros de la organización, incluidos los gerentes (1-2).

Según Tigani (3), la excelencia del servicio es necesaria en cualquier organización como estrategia de mercadeo por satisfacción y los efectos que genera permiten conocer que:

a. E1 $96 \%$ de los clientes insatisfechos nunca se queja, simplemente se va y nunca vuelve.

b. Los clientes muy satisfechos trasmiten su satisfacción a tres o menos personas.

c. Los clientes insatisfechos trasmiten su insatisfacción a nueve o más personas.

d. Cuesta hasta cinco veces más conseguir un nuevo cliente que venderle a un cliente existente.

e. El cliente tiene un valor de por vida, que es todo lo que puede consumir de la organización durante su existencia (3).

Etimológicamente, servicio viene de servus (siervo) y esta palabra se originó cuando en las batallas los vencedores ya no aniquilaban a los vencidos sino que reservaban algunos para realizar diferentes oficios humildes, útiles al vencedor y al ejército. En la actualidad empresarial, el servicio tiene una connotación muy diferente aunque en muchas partes y, especialmente en este medio, parece que se asimila más al siervo de la antigüedad. Se entiende por servicio el valor agregado en toda transacción o intercambio entre personas, entidades o ambas, que aumenta en forma intangible el valor en sí y predispone en forma positiva a los participantes para continuar la relación establecida y para futuros intercambios o transacciones (4).

La excelencia consiste, entonces, en conocer, satisfacer y sorprender a los clientes. Es necesario agregarle valor al servicio que se ofrece. Este valor lo constituye el conjunto de cosas intangibles y tangibles que determinan, para el cliente, el valor integral del servicio ofrecido, convirtiéndose en momentos de verdad, es decir, en cada contacto que el cliente hace con la organización y lo evalúa según la satisfacción que le produzca (5-6).

Un momento de verdad "es un episodio en el cual un cliente hace contacto con algún aspecto de la organización, por remoto que sea, y debido a eso tiene oportunidad de formarse una impresión" (5). El problema y reto, desde este punto de vista, consiste en que la mayor parte de los momentos de verdad se presentan muy lejos del campo visual inmediato de la gerencia, razón que sustenta la necesidad de crear una organización orientada hacia el cliente, un sistema amable que permita la satisfacción de éste y también la existencia de un ambiente de trabajo que refuerce la idea de poner al cliente en primer lugar (5-6).

Los momentos de la verdad implican una interacción directa entre los empleados y los clientes, sin indicar si es positiva o negativa. Cuando el cliente observa un aviso de su empresa, recibe una factura o un resumen por correo, escucha una voz grabada por el teléfono, abre un paquete que llegó a su casa o pide una cita, cada una de estas situaciones conduce a una impresión sobre el servicio prestado. La suma total de todos los posibles momentos de verdad que experimentan los clientes, intervengan o no las personas, constituye la imagen del servicio (7). 
La tendencia hacia el consumismo, el variable clima competitivo y las recesiones recurrentes ha obligado a las empresas y organizaciones a hacer una revisión de sus relaciones con el cliente. En consecuencia, el servicio al cliente se ha convertido en una herramienta estratégica considerada como una fuerza positiva para incrementar las ventas y para obtener una mayor satisfaccion de éste (7).

Albrecht y Zemke (7) y Berry (8) mencionan que para lograr la excelencia del servicio se deben fortalecer las siguientes dimensiones en una organización:

A. Respuesta: la capacidad de respuesta manifiesta el grado de preparación de la organización para satisfacer las necesidades.

B. Atención: no se debe dar lugar a la apatía, la indiferencia o el desprecio.

C. Comunicación: demostrar que se entiende al cliente y expresarse en términos acordes con su nivel permite establecer una comunicación clara.

D. Accesibilidad: facilitar la interacción y el acceso a los servicios o personas de la institución genera excelencia.

E. Amabilidad: se debe tener la capacidad para demostrar afecto.

F. Credibilidad: nunca se debe mentir ni ofrecer cosas inalcanzables al cliente.

G. Comprensión: es necesario esforzarse por entender qué significa el servicio para el cliente.

Asi mismo, Albrecht y Zemke (7) señalan que los parametros fundamentales para lograr la excelencia estan orientados a:

- Fuera de competencia: nunca se debe manifestar la incompetencia.

- Mediocridad: es el nivel máximo donde no se tienen en cuenta las expectativas del cliente, detalladas en cada uno de los momentos de verdad.

- Presencia y responsabilidad: es pensar en invertir con base en necesidades reales de los clientes, para obtener un mejor servicio.
- Demostrar compromisos serios con el cliente: un compromiso es una promesa hecha al cliente que se debe hacer realidad para lograr su fidelización.

- Ser excelente: es el nivel más alto donde se superan las expectativas del cliente.

- Mantener la necesidad de la mejora continua: es necesario tener en cuenta que las expectativas del cliente aumentan o se modifican. 


\section{REFERENCIAS BIBLIOGRÁFICAS}

ISSN 1794-9831

E-ISSN 2322-7028

Vol. 13 No. 2

1. Arcelús G. Atención al ciudadano. Subsecretaria para la modernización del estado. Argentina: Instituto Provincial de la Administración Pública (IPAP); 2008.

2. González-Méndez E. Calidad de la atención en el servicio de urgencias del área de salud Heredia Cubujuquí desde la perspectiva del cliente. San José, Costa Rica Junio; Instituto Centroamericano de Administración Pública ICAP; 2008.

3. Tigani ND. La excelencia en servicio. Argentina; Liderazgo 21; 2006.

4. Pérez-Sánchez F. Conferencia Internacional de Ciencias Empresariales - La filosofía del servicio al cliente orientada a Latinoamérica. Colombia: INPEFRA Ingenieros. p. 64

5. Carlzon J. El Momento de la Verdad. Madrid: Ediciones Díaz de Santos S.A.; 1991. ISBN: 84-87189-76-8.

6. República de Colombia, Ministerio de Salud. Programa de mejoramiento de los servicios de salud en Colombia. Ingeniería del servicio. Módulo 10. Bogotá: Ministerio de Salud; 1996. p. 49.

7. Albrecht K, Zemke R. Gerencia del Servicio. Bogotá: Editorial Legis; 1991. ISBN: 958- 9042-34-1.

8. Berry L. Un buen servicio ya no basta: cuatro principios del servicio excepcional al cliente. Bogotá: Editorial Norma; 2002. ISBN 958-04-6720-X. 